\title{
Development of the Deep Cerebellar Nuclei: Transcription Factors and Cell Migration from the Rhombic Lip
}

\author{
Andrew J. Fink, Chris Englund, Ray A. M. Daza, Diane Pham, Charmaine Lau, Mary Nivison, Tom Kowalczyk, and \\ Robert F. Hevner \\ Department of Pathology (Neuropathology), University of Washington, Seattle, Washington 98104
}

The deep cerebellar nuclei (DCN) are the main output centers of the cerebellum, but little is known about their development. Using transcription factors as cell type-specific markers, we found that DCN neurons in mice are produced in the rhombic lip and migrate rostrally in a subpial stream to the nuclear transitory zone (NTZ). The rhombic lip-derived cells express transcription factors Pax6, Tbr2, and Tbr1 sequentially as they enter the NTZ. A subset of rhombic lip-derived cells also express reelin, a key regulator of Purkinje cell migrations. In organotypic slice cultures, the rhombic lip was necessary and sufficient to produce cells that migrate in the subpial stream, enter the NTZ, and express Pax6, Tbr2, Tbr1, and reelin. In later stages of development, the subpial stream is replaced by the external granular layer, and the NTZ organizes into distinct DCN nuclei. Tbr1 expression persists to adulthood in a subset of medial DCN projection neurons. In reeler mutant mice, which have a severe cerebellar malformation, rhombic lip-derived cells migrated to the NTZ, despite reelin deficiency. Studies in Tbr1 mutant mice suggested that Tbrl plays a role in DCN morphogenesis but is not required for reelin expression, glutamatergic differentiation, or the initial formation of efferent axon pathways. Our findings reveal underlying similarities in the transcriptional programs for glutamatergic neuron production in the DCN and the cerebral cortex, and they support a model of cerebellar neurogenesis in which glutamatergic and GABAergic neurons are produced from separate progenitor compartments.

Key words: Brn2; fastigial nucleus; Pax6; reeler; Tbr2; Tbr1

\section{Introduction}

The deep cerebellar nuclei (DCN) are the main output centers of the cerebellum (Voogd, 1995), but relatively little is known about their development. The DCN contain two types of neurons, glutamatergic projection neurons and GABAergic interneurons, which develop according to different timetables. Glutamatergic projection neurons are produced first, from embryonic day 10.5 (E10.5) to E12.5 in mice (Miale and Sidman, 1961). They initially coalesce in the nuclear transitory zone (NTZ), which is located just below the pial surface at the rostral end of the cerebellar plate (Goffinet, 1983; Altman and Bayer, 1985b). Subsequently, GABAergic interneuron precursors are produced from E13.5 to E16.5 from progenitor cells in the cerebellar ventricular zone (VZ) (Maricich and Herrup, 1999). The GABAergic interneuron precursors express transcription factor Pax 2 and continue to divide during the first postnatal week as they migrate through developing white matter to the DCN and cerebellar cortex (Zhang and Goldman, 1996; Maricich and Herrup, 1999).

The embryonic origins of DCN glutamatergic neurons have been undefined. Previous morphological studies suggested that

Received June 5, 2005; revised Jan. 30, 2006; accepted Feb. 2, 2006.

This work was supported by the National Institutes of Health (K02 NS045018) and the Edward Mallinckrodt, Jr. Foundation. We thank Dr. J. Mason and Dr. D. Price for tau-GFPtransgenic mice; Dr. R. McEvilly and Dr. M. Rosenfeld for anti-Brn2; and Dr. R. Edwards for VGLUT1 and VGLUT2 CDNA. We thank Dr. J. Cooper for comments on a previous version of this manuscript.

Correspondence should be addressed to Dr. Robert F. Hevner, Harborview Pathology, Box 359791, 325 Ninth Avenue, Seattle, WA 98104. E-mail: rhevner@u.washington.edu.

DOI:10.1523/JNEUROSCI.5203-05.2006

Copyright $\odot 2006$ Society for Neuroscience $\quad$ 0270-6474/06/263066-11\$15.00/0 glutamatergic DCN neurons, like GABAergic neurons, originate mainly in the cerebellar VZ (Altman and Bayer, 1985a,b). In addition, a contribution of migrating cells from the rhombic lip has been described in some studies (Korneliussen and Jansen, 1965; Korneliussen, 1967). Recently, genetic lineage tracing with Math1, a rhombic lip marker (Ben-Arie et al., 1997), suggested that the rhombic lip may actually produce the majority of DCN projection neurons (Machold and Fishell, 2005; Wang et al., 2005).

To investigate the origins and migrations of $\mathrm{DCN}$ projection neurons, we studied transcription factors Pax6, Tbr1, and Tbr2 in the developing cerebellum (Bulfone et al., 1995, 1999; Engelkamp et al., 1999). The transcription factor expression patterns suggested that DCN neurons migrate from the rhombic lip to the NTZ through a subpial migration pathway while expressing Pax6, Tbr2, and Tbr1 sequentially. Experiments in organotypic slice cultures supported this conclusion. Reelin ${ }^{+}$cells, which are scattered along the subpial pathway (Miyata et al., 1996), likewise appeared to originate from the rhombic lip. To determine whether reelin or Tbr1 is necessary for DCN development, we studied reeler (Goffinet, 1983) and Tbr1 mutant mice (Bulfone et al., 1998). Both mutant strains showed abnormalities of DCN morphogenesis, although neither gene appears to be required for cell migration from the rhombic lip to the NTZ.

Our findings support the conclusion that most DCN projection neurons originate from the rhombic lip and express specific developmental transcription factor profiles. Interestingly, the order of Pax6, Tbr2, and Tbr1 sequential expression in DCN pro- 
jection neurons is similar to that in projection neurons of the developing cerebral cortex (Englund et al., 2005). Because DCN and other cerebellar glutamatergic neurons come from the rhombic lip, we propose that cerebellar neurogenesis, like forebrain neurogenesis (Schuurmans and Guillemot, 2002), may be compartmentalized. Glutamatergic (and some cholinergic) neurons appear to be produced in the rhombic lip, whereas GABAergic neurons are produced in the cerebellar VZ. This model provides a framework for understanding progenitor cell types and cell migrations in cerebellar development.

\section{Materials and Methods}

Animals and tissue preparation. Mice were studied under a protocol approved by the Institutional Animal Care and Use Committee at the University of Washington. B6 mice and reeler mice were from The Jackson Laboratory (Bar Harbor, ME). Tbr1 mutant mice (Bulfone et al., 1998) were from John Rubenstein (University of California San Francisco). Tau-GFP transgenic mice (Pratt et al., 2000) were from Dr. J. Mason and Dr. D. Price (University of Edinburgh, Edinburgh, UK). Details of animal procedures have been described previously (Hevner et al., 2004). For bromodeoxyuridine (BrdU) labeling, timed-pregnant dams (plug day $=$ E0.5) were given BrdU by intraperitoneal injection ( $40 \mathrm{mg} / \mathrm{kg}$ ). For histological studies, embryos were removed and immersion-fixed after Avertin anesthesia of the dam. Neonatal pups were perfused under cryoanesthesia, and older mice were perfused under Avertin anesthesia. The fixative was cold buffered $4 \%$ paraformaldehyde. Brains were fixed for $16-20 \mathrm{~h}$ at $4^{\circ} \mathrm{C}$, rinsed, cryoprotected with sucrose, and frozen in OCT. Sections were cut at $10-12 \mu \mathrm{m}$, air dried, and stored at $-80^{\circ} \mathrm{C}$.

Organotypic slice cultures of developing cerebellum. Procedures generally followed those of Anderson et al. (1997). Embryos from tau-GFP heterozygote/B6 crosses were removed on E11.5 or E12.5 under Avertin anesthesia. The embryos were placed in HBSS on ice. The brains were removed and placed in Kreb's buffer on ice. Midbrain-hindbrain blocks were embedded in $4 \%$ low-melting-point agarose and sliced sagittally on a vibratome $(300 \mu \mathrm{m})$. Vibratome slices through cerebellum were transferred to polycarbonate membranes $(13 \mathrm{~mm}$; Nuclepore, Whatman, Maidstone, UK) floating on $10 \%$ fetal calf serum-supplemented media (MEM with glutamine and penicillin-streptomycin; Invitrogen, Carlsbad, CA $)$ in center-well culture plates $(60 \times 15 \mathrm{~mm}$; Falcon, BectonDickinson, Mountain View, CA) and cultured at the gas-liquid interface at $37^{\circ} \mathrm{C}$ with $5 \% \mathrm{CO}_{2}$. E12.5 slices produced the best results and were studied in three different configurations: (1) control slices were left intact $(n=5)$; (2) ablated slices had the rhombic lip removed with a scalpel $(n=5)$; and (3) cocultured slices had the endogenous (nontransgenic) rhombic lip replaced with the rhombic lip from a tau-GFP transgenic littermate embryo $(n=12)$. Slices were cultured for $2 \mathrm{~d}$ in serum-free Neurobasal/B27 media (Invitrogen) and then fixed for 4-6 h in cold buffered $4 \%$ paraformaldehyde. The fixed slices were rinsed with PBS, cryoprotected with sucrose, frozen, and cryosectioned as for brain tissues.

Terminal deoxynucleotidyl transferase-mediated biotinylated UTP nick end labeling to detect apoptosis. The Cell Death Detection Kit, Fluorescein (Roche Products, Welwyn Garden City, UK) was used as recommended by the manufacturer and as described (Hevner et al., 2004).

Axon tracing with DiI. Fixed brains from embryonic or neonatal mice were dissected posteriorly to reveal the deep nuclei or vestibular nuclei or dissected anteriorly to reveal the red nuclei. Single or multiple small crystals of $\mathrm{DiI}$ ( $\leq 100 \mu \mathrm{m}$ each) were placed in the locations described for each experiment. Tissue specimens were stored in PBS with $0.01 \%$ azide. After 4-12 weeks for DiI diffusion, tissues were embedded in $4 \%$ lowmelt agarose, sectioned on a vibratome, processed for fluorescence immunohistochemistry, and counterstained with $0.01 \% 4^{\prime}, 6^{\prime}$-diamidino2-phenylindole (DAPI) (Sigma, St. Louis, MO) as indicated (Hevner et al., 2002).

Axon tracing with cholera toxin B-Alexa 488. Cholera toxin B-Alexa 488 (CTB-A488) (Invitrogen) was injected into the upper cervical spinal cord of postnatal mice under isoflurane anesthesia as described (Hevner et al., 2003). After 3-5 d for retrograde transport, animals were perfused with fixative. The brains were removed, postfixed, cryosectioned, and processed for immunofluorescence.

Immunofluorescence. Slides were boiled briefly in $10 \mathrm{~mm}$ sodium citrate, $\mathrm{pH}$ 6.0, for antigen enhancement. Sections were treated with primary antibodies and fluorescent secondary antibodies as described (Hevner et al., 2004). To label DNA, sections were counterstained with DAPI or $0.1 \mu \mathrm{M}$ TO-PRO-3 (Invitrogen). For Tbr1-glutamate or Tbr1GABA double labeling, sections were first processed for glutamate or GABA by the avidin-biotin complex method (Vector Laboratories, Burlingame, CA) with diaminobenzidine as chromogen (Hevner et al., 2001) and then for Tbrl immunofluorescence. Bright-field gray scale images of glutamate or GABA immunoreactivity were then inverted with Photoshop (Adobe, San Jose, CA) and pasted into a different RGB channel from Tbr1 immunofluorescence to produce pseudo two-color immunofluorescence. For Tbr1-Tbr2 double-labeling images, adjacent sections were processed for Tbr 1 or Tbr2, and the separate images were combined in Photoshop. Double immunofluorescence combining green fluorescent protein (GFP) with other markers was accomplished by a two-step primary antibody procedure during which sections were fixed for $30 \mathrm{~min}$ after GFP primary antibody incubation, rinsed, reacted with primary antibodies against the second antigen, and then processed further with secondary antibodies as usual.

Primary antibodies. Mouse monoclonal antibodies were as follows: anti-BrdU (1:200) and anti-neuronal-specific nuclear protein (NeuN) (1:1500) from Chemicon (Temecula, CA); anti-Pax6 (1:2000) from Developmental Studies Hybridoma Bank (Iowa City, IA); G10 anti-reelin (1:1000) from Calbiochem (La Jolla, CA); anti-calbindin (1:3000) from Sigma; anti-glial fibrillary acidic protein (1:100) from DakoCytomation (Carpinteria, CA); nonphosphorylated neurofilament H (SMI-32; 1:1000) from Sternberger Monoclonals (Lutherville, MD); and anti- $\beta$ IIItubulin (1:1000) from Covance (Princeton, NJ). Rat monoclonal antibody was anti-BrdU (1:200) from Harlan Sera-Lab (Loughborough, UK). Rabbit polyclonal antibodies were anti-calretinin (1:2000) from Swant (Bellinzona, Switzerland); anti-GABA (1:2000) and antiglutamate $(1: 15,000)$ from Sigma; anti-Pax2 (1:750) from Zymed (San Francisco, CA); and anti-Tbr1 (1:2500) and anti-Tbr2 (1:2000) from the R. F. Hevner laboratory (Englund et al., 2005). Guinea pig polyclonal antibody was anti-Brn2 from R. McEvilly and M. Rosenfeld (University of California San Diego).

In situ hybridization. In situ hybridization was done with digoxigeninlabeled probes for vesicular glutamate transporter 1 (VGLUT1) or VGLUT2 mRNA, with immunodetection and 5-bromo-4-chlor-indolylphosphate-nitroblue tetrazolium chloride histochemistry with a kit (Roche Products) as described (Hevner et al., 2001). For double labeling with Tbr1, sections were postfixed for $4-6 \mathrm{~h}$ after in situ hybridization and then reacted for Tbr1 immunofluorescence. Bright-field images of VGLUT1 or VGLUT2 mRNA were combined with Tbr1 immunofluorescence in Photoshop.

Microscopy. Epifluorescence and confocal imaging were done as described (Englund et al., 2005).

\section{Results}

\section{Pax6, Tbr2, and Tbr1 are expressed in sequence from the rhombic lip to the NTZ}

Pax6, Tbr2, and Tbr1 protein were first detected in the rhombic lip and the NTZ from E11.5 to E12.5 (data not shown). On E13.5, all three transcription factors showed strong expression, and together they demarcated a continuous pathway, which was interpreted as a subpial stream of cell migration from the rhombic lip to the NTZ (Fig. 1). Pax6 was expressed in the rhombic lip, in the subpial stream, and in cells entering the NTZ (Fig. 1A-F). Tbr2 was expressed in cells at the transition from the subpial stream to the NTZ and in NTZ cells proximal to the subpial stream (Fig. $1 C, D, G, H)$. Tbr 1 was expressed in NTZ cells, mainly distal to the subpial stream (Fig. 1A,B,I,J). Confocal imaging showed that Pax6 was coexpressed with Tbr1 (Fig. $1 B$ ) and Tbr2 (Fig. 1D) in cells as they entered the NTZ. This suggested that cells concur- 

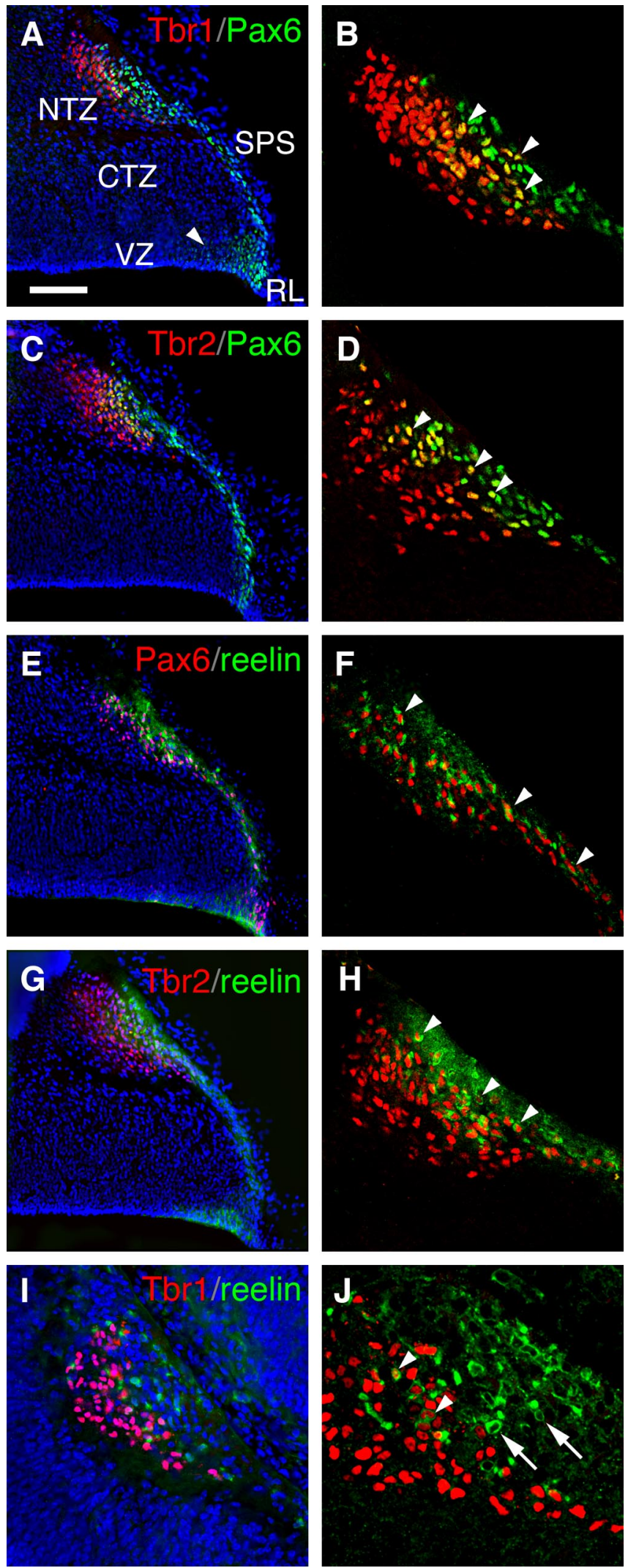

Figure 1. Transcription factors and reelin expression in E13.5 cerebellum. Sagittal sections (dorsal, top; rostral, left) were processed for double immunofluorescence and counterstained with DAPI (blue). $\boldsymbol{A}, \boldsymbol{B}, \mathrm{Tbr} 1$ (red) and Pax6 (green). Pax6 ${ }^{+}$cells migrated from the rhombic lip (RL) through the subpial stream (SPS) to enter the NTZ, where Pax6 was downregulated and Tbr1 was upregulated. Pax6 and Tbr1 were coexpressed in some cells at the SPS-NTZ interface ( $\boldsymbol{B}$, arrowheads). Pax6 was also expressed in a small segment of the VZ adjacent to the RL $(\boldsymbol{A}$, arrowhead). (TZ, Cortical transitory zone. C, D, Tbr2 (red) and Pax6 (green). Tbr2 was expressed rently upregulated Tbr2 and Tbr1 and downregulated Pax6 as they left the subpial stream and entered the NTZ. Expression patterns within the NTZ suggested that Tbr1 was upregulated slightly later than Tbr2 and continued to be expressed longer than Tbr2.

To investigate the possibility that reelin ${ }^{+}$cells in the NTZ (Miyata et al., 1996) originate from the rhombic lip, we compared the expression of reelin and transcription factors by double immunofluorescence. Reelin showed expression patterns that were remarkably similar to Pax6, extending from the rhombic lip along the subpial stream to the proximal NTZ (Fig. $1 E-J$ ). Confocal imaging showed that virtually all reelin ${ }^{+}$cells expressed Pax6, although not all $\mathrm{Pax}^{+}$cells expressed reelin (Fig. $1 F$ ). Some reelin ${ }^{+}$cells in the NTZ expressed Tbr2 (Fig. 1G,H), but few expressed Tbr1 (Fig. 1I,J). These results suggested that ree$\mathrm{lin}^{+}$cells in the subpial stream and the NTZ represent a subset of Pax $^{+}$cells from the rhombic lip.

\section{Rhombic lip cells migrate to the NTZ in organotypic slice cultures}

To test directly whether cells migrate from the rhombic lip to the NTZ, we studied the embryonic cerebellum in organotypic slice cultures. Sagittal slices from E12.5 embryos were cultured for $2 \mathrm{~d}$ in vitro (DIV) in three different configurations. First, as a control to assess whether the rhombic lip and the NTZ develop normally in slice culture, some tissue slices were cultured without any experimental manipulations (Fig. 2A). In these control experiments, the rhombic lip, the subpial stream, and the NTZ appeared to develop normally, as evidenced by Pax6, Tbr2, and Tbr1 expression patterns (Fig. $2 B-D$ ).

Second, to test whether the rhombic lip is necessary for the development of the subpial stream and the NTZ, another set of tissue slices was treated by rhombic lip ablation at the start of the culture period, leaving the cerebellar VZ intact (Fig. 2E). This resulted in severe reduction or absence of the subpial stream after 2 DIV, as indicated by loss of Pax6 (Fig. 2F) and Tbr2 (Fig. 2G) expression. Tbr ${ }^{+}$cells were reduced but not absent in the NTZ (Fig. $2 H$ ), probably because some NTZ cells were born and entered the subpial stream before E12.5, when rhombic lip ablation was finished. Consistent with this interpretation, previous studies have shown that DCN projection neurons are born from E10.5 to E12.5 (Miale and Sidman, 1961).

Third, to directly trace cell migration, the endogenous nontransgenic rhombic lip was replaced with the rhombic lip from a tau-GFP transgenic littermate embryo (Fig. 2I). Cells that migrated from the tau-GFP transgenic rhombic lip into the nontransgenic cerebellar slice were identified on the basis of tau-GFP fusion protein fluorescence or immunoreactivity. After 2 DIV, many tau-GFP ${ }^{+}$cells had migrated from the rhombic lip into the subpial stream and the NTZ (Fig. $2 J-L$ ). Significantly, the tau$\mathrm{GFP}^{+}$cells expressed Pax6, Tbr2, and Tbr1 in patterns (Fig. $2 M-O$ ) identical to those observed in vivo (Fig. 1) and in control slices (Fig. $2 B-D$ ). Moreover, the tau-GFP ${ }^{+}$cells migrated to the same positions as endogenous (tau-GFP ${ }^{-}$) cells that expressed

\section{$\leftarrow$}

in a subset of NTZ cells and was coexpressed with Pax6 in cells at the SPS-NTZ interface ( $\boldsymbol{D}$, arrowheads). $\boldsymbol{E}, \boldsymbol{F}$, Pax6 (red) and reelin (green). Reelin was expressed in a subset of Pax ${ }^{+}{ }^{+}$cells ( $\boldsymbol{F}$, arrowheads) in the RL, SPS, and NTZ. G, $\boldsymbol{H}$, Tbr2 (red) and reelin (green). Tbr2 and reelin overlapped only in cells at the SPS-NTZ interface $(\boldsymbol{H}$, arrowheads). $\boldsymbol{I}, \boldsymbol{J}$, Tbr1 (red) and reelin (green). Tbr1 and reelin overlapped in a few cells at the SPS-NTZ interface (I, arrowheads), but most reelin ${ }^{+}$cells did not express Tbr1 (J, arrows). Scale bar: (in $\left.\boldsymbol{A}\right) \boldsymbol{A}, \boldsymbol{C}, \boldsymbol{E}, \boldsymbol{G}, 100 \mu \mathrm{m} ; \boldsymbol{B}, \boldsymbol{D}, \boldsymbol{F}$, H, I, $50 \mu \mathrm{m} ; \boldsymbol{J}, 25 \mu \mathrm{m}$. 

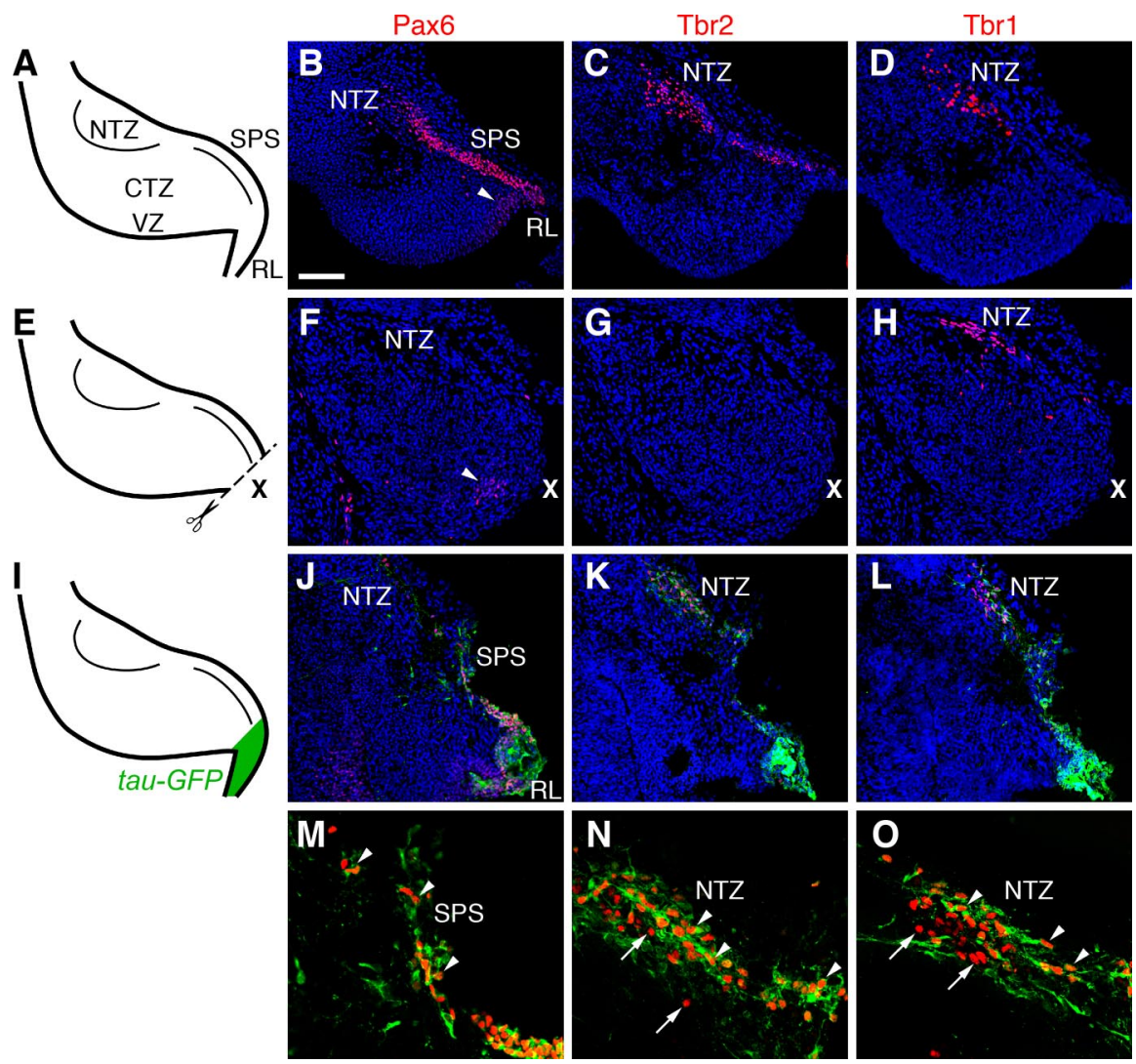

Figure 2. Transcription factor expression and cell migration in organotypic slice cultures. Sagittal slices (300 $\mu \mathrm{m}$ ) of E12.5 cerebellum and brainstem were cultured for 2 DIV and then fixed and cryosectioned $(12 \mu \mathrm{m})$. Serial cryosections were then processed for immunofluorescence to detect Pax6, Tbr2, or Tbr1 (red) with GFP (green), and counterstained with DAPI (blue). $\boldsymbol{A}_{\text {, }}$ Anatomy of E12.5 cerebellar slices (dorsal, top; rostral, left). CTZ, Cortical transitory zone. $\boldsymbol{B}-\boldsymbol{D}$, Expression of Pax6 (B), $\operatorname{Tbr} 2(\boldsymbol{C})$, and Tbr1 (D) in a control slice [rhombic lip (RL) intact]. Expression patterns recapitulated those in vivo (Fig. 1), notably including Pax6 expression in the VZ adjacent to the rhombic lip ( $\boldsymbol{B}$, arrowhead). $\boldsymbol{E}$, In ablation experiments, the rhombic lip was physically removed $(X)$ at the start of slice culture. $\boldsymbol{F}-\boldsymbol{H}$, Expression of Pax6 $(\boldsymbol{F})$, Tbr2 $(\boldsymbol{G})$, and Tbr1 $(\boldsymbol{H})$ in a rhombic lip-ablated slice. The subpial stream (SPS) was completely depleted, as indicated by a lack of Pax6 ${ }^{+}$cells and Tbr2 ${ }^{+}$cells. A few Pax ${ }^{+}$cells persisted in the VZ adjacent to the rhombic lip ( $\boldsymbol{F}$, arrowhead). Tbr $1^{+}$cells in the NTZ $(\boldsymbol{H})$ were presumably born before E12.5. $\boldsymbol{I}$, In slice- explant coculture experiments, the rhombic lip was replaced with rhombic lip from a tau-GFP transgenic littermate. J-0, Expression of $\operatorname{Pax} 6(\boldsymbol{J}, \boldsymbol{M}), \operatorname{Tbr} 2(\boldsymbol{K}, \boldsymbol{N}), \operatorname{Tbr} 1(\boldsymbol{L}, \mathbf{O})$, and tau-GFP $(\boldsymbol{J}-\mathbf{O})$ in a coculture experiment. The subpial stream was reconstituted with tau-GFP ${ }^{+}$cells, many of which migrated to the NTZ. Confocal imaging $(\boldsymbol{M}-\mathbf{0})$ demonstrated that many tau-GFP ${ }^{+}$cells coexpressed Pax6 in the subpial stream ( $\boldsymbol{M}$, arrowheads), and Tbr2 and Tbr1 in the NTZ ( $\boldsymbol{N}, \mathbf{0}$, arrowheads). Significantly, cells from the tau-GFP transgenic rhombic lip migrated to the NTZ location as defined by endogenous (nontransgenic) $\mathrm{Tbr} 2^{+}$cells and $\mathrm{Tbr}{ }^{+}$cells $(\boldsymbol{N}, \mathbf{O}$, arrows), suggesting that migration cues and responses were intact. Scale bar: (in $\boldsymbol{B}$ ) $B-D, F-H, 100 \mu \mathrm{m} ; \boldsymbol{I}-\boldsymbol{K}, 25 \mu \mathrm{m}$.

Tbr2 and Tbr1 (Fig. 2N,O), indicating that rhombic lip cells migrated to the NTZ. This migratory pathway was not an artifact of the culture system, because identical experiments with slices from older embryos produced different migration patterns (C. Englund and R. Hevner, unpublished observations).

These results in organotypic slice cultures (Fig. 2) supported our conclusion, based on studies in the intact cerebellum (Fig. 1), that Pax6, Tbr2, and Tbr1 expression demarcate a cell migration pathway from the rhombic lip to the NTZ.

\section{Tbr1 expression persists in a subset of medial DCN projection neurons}

To investigate the further development of NTZ cells derived from the rhombic lip, we studied transcription factor expression at later embryonic and postnatal ages. Pax6 and Tbr2 were rapidly downregulated in NTZ cells (data not shown; Englund and Hevner, unpublished observations), but Tbr1 expression was maintained throughout the NTZ until E14.5 and in medial DCN nuclei into adulthood (Fig. 3). Tbr1 expression decreased in lateral and interposed nuclei of the DCN between E14.5 and E16.5 (Fig. 3D-I). In contrast, Brn2, a POU-domain transcription factor, was expressed in lateral and interposed nuclei, but not in medial DCN nuclei, during the neonatal period (Fig. 3J,K). Thus, the medial- and lateral-interposed DCN nuclei showed differences of transcription factor expression, which may relate to differences in axonal connections or other neuronal properties.

The mature DCN contain a heterogeneous cellular population of early-born glutamatergic neurons, later-born GABAergic neurons, and glial cells. To characterize the phenotypes of $\mathrm{Tbr} 1^{+}$ cells, we labeled cell "birthdays" with BrdU and studied a panel of neuronal and glial markers. Tbr ${ }^{+}$cells were born mainly from E10.5 to E12.5 (Fig. 4), as expected for DCN projection neurons (Miale and Sidman, 1961). Acute BrdU labeling in embryos showed that Tbr ${ }^{+}$cells in the NTZ are postmitotic (data not shown). The neuronal phenotype of Tbr1 ${ }^{+}$cells was demonstrated by colocalization with NeuN (Fig. 5D), and by lack of colocalization with glial fibrillary acidic protein (data not shown). NeuN immunoreactivity was weak in some $\mathrm{Tbr} 1^{+}$ cells, consistent with previous observations of DCN neurons (Weyer and Schilling, 2003). Not all $\mathrm{NeuN}^{+}$neurons in the DCN expressed Tbr1, indicating that Tbr $1^{+}$cells represent only a subset of neurons in medial deep nuclei.

Calretinin is a dynamic marker of cells and axons in the developing cerebellum and brainstem (Abbott and Jacobowitz, 1995); however, the identity of some calretinin ${ }^{+}$elements in the medial cerebellum and adjacent cerebellar cortex "hot spot" (Abbott and Jacobowitz, 1995) has been undetermined. We found that calretinin was expressed by a subset of Tbr ${ }^{+}$cells in the medial DCN from E17.5 to postnatal ages (Fig. $5 A, B$ ). Our results suggested that the Tbr $1^{+}-$calretinin $^{+}$cells in the medial DCN are projection neurons that send axons to the contralateral medial DCN through the hook bundle (Fig. 5A). Calretinin ${ }^{+}$cells in the cerebellar cortex hot spot did not express Tbr1 but did express calbindin (data not shown), suggesting that they were possibly a subset of Purkinje cells. Also, some calretinin ${ }^{+}-\mathrm{Tbr} 1^{-}$cells in the E17.5 cerebellum may have been unipolar brush cells (Kalinichenko and Okhotin, 2005), which express Tbr2 but not Tbr1 (Englund and Hevner, unpublished observations).

To evaluate the neurotransmitter phenotype of Tbr $1^{+}$cells, we studied markers of GABAergic and glutamatergic differentiation. We first compared Tbr1 against Pax2, a marker of GABAergic interneuron precursors (Maricich and Herrup, 1999). Because antibodies against Tbr 1 and Pax 2 are both polyclonal, they could not be combined for double immunofluorescence in the 

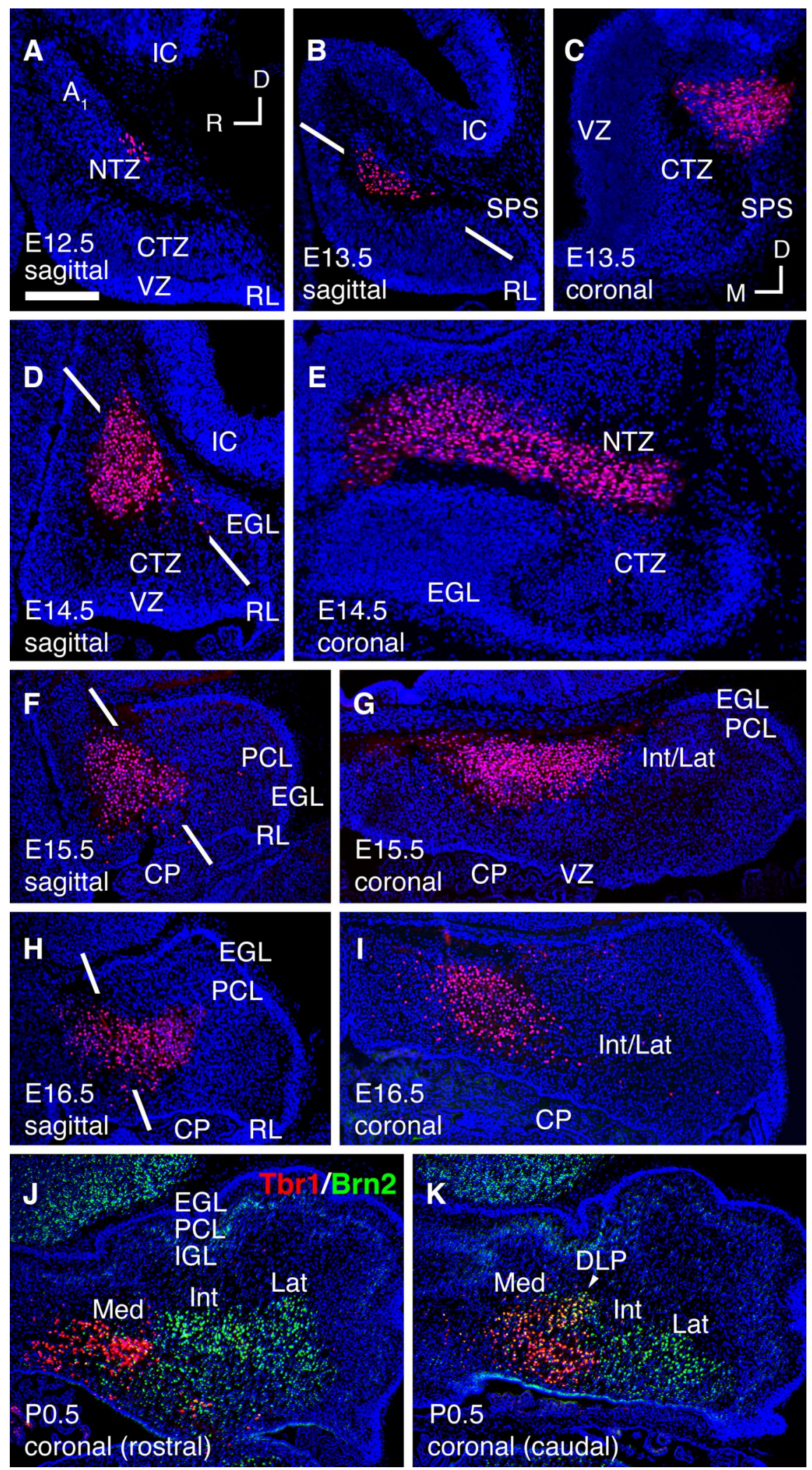

Figure 3. Dynamics of Tbr1 expression in cerebellar development. Immunofluorescence detection of $\operatorname{Tbr} 1(\boldsymbol{A}-\boldsymbol{K}$, red) and $B r n 2$ $\left(\boldsymbol{J}, \boldsymbol{K}\right.$, green) with DAPI (blue) counterstain. $\boldsymbol{A}, \mathrm{E} 12.5$, sagittal. The NTZ contained a few Tbr ${ }^{+}$cells. $\boldsymbol{B}, \boldsymbol{C}, \mathrm{E} 13.5$, sagittal $(\boldsymbol{B})$ and coronal ( $(\boldsymbol{C})$; lines in $\boldsymbol{B}$ indicate plane of $\boldsymbol{C} . \boldsymbol{D}, \boldsymbol{E}, \mathbf{E} 14.5$, sagittal $(\boldsymbol{D})$ and coronal $(\boldsymbol{E})$; lines in $\boldsymbol{D}$ indicate plane of $\boldsymbol{E}$. Tbr1 was expressed throughout the NTZ at all mediolateral levels. $\boldsymbol{F}, \boldsymbol{G}$, E15.5, sagittal $(\boldsymbol{F})$ and coronal $(\boldsymbol{G})$; lines in $\boldsymbol{F}$ indicate plane of $\boldsymbol{G}$. Tbr1 was expressed in medial deep nuclei but not in interposed (Int) and lateral (Lat) deep nuclei. $\boldsymbol{H}, \boldsymbol{I}$, E16.5, sagittal $(\boldsymbol{H})$ and coronal $(\boldsymbol{I})$; lines in $\boldsymbol{H}$ indicate plane of $\boldsymbol{I}$. Tbr 1 was expressed in a subset of medial deep nuclei cells. This pattern continued through subsequent development into adulthood. $\boldsymbol{J}, \boldsymbol{K}$, P0.5 coronal sections, rostral $(\boldsymbol{J})$ and caudal $(\boldsymbol{K})$. Tbr1 was expressed in medial (Med) deep nuclei, whereas Brn2 was expressed in interposed and lateral nuclei. Both Tbr1 and Brn2 were expressed in the dorsolateral same section. Instead, we compared each transcription factor with calbindin, a marker of Purkinje cells and their axons. $\mathrm{Tbr}^{+}$neurons were abundant within the DCN region delimited by calbindin ${ }^{+}$processes (Fig. 5C). In contrast, most Pax $2^{+}$ cells were located outside the calbindinrich DCN (Fig. 5E). Also, Tbr ${ }^{+}$cells did not contain GABA (Fig. 5F). Together, these data suggested that $\mathrm{Tbr} 1^{+}$cells are not GABAergic interneurons or precursors. On the other hand, virtually all $\mathrm{Tbr}^{+}$cells displayed a glutamatergic phenotype, as indicated by VGLUT2 mRNA expression (Fig. 5G) (Fremeau et al., 2001), and by high levels of intracellular glutamate (Fig. $5 H$ ). In addition, a small proportion of Tbr $1^{+}$cells expressed VGLUT1 mRNA (data not shown). Notably, not all of the glutamate ${ }^{+}$cells expressed Tbr1 (Fig. 5H), indicating that Tbr1 marks a subset of glutamatergic projection neurons.

Finally, we compared Tbr1 with SMI32 , an antibody that detects neurofilament proteins in the DCN and other regions (Fig. 5I,J). SMI-32 has been used recently as a marker of large glutamatergic neurons in the DCN (Hoshino et al., 2005). Tbr1 and SMI-32 were coexpressed in some large neurons, but other cells expressed either Tbr1 or SMI-32 exclusively (Fig. $5 I, J)$. These results suggested that Tbr 1 and SMI-32 identify partially overlapping subsets of glutamatergic neurons.

Tbr ${ }^{+}$neurons project to vestibular nuclei, spinal cord, and contralateral deep nuclei, but not red nuclei

Our finding that Tbr $1^{+}$cells represent a subset of glutamatergic neurons suggested that Tbr1 might be expressed by neurons that project to specific targets. As noted above, calretinin immunoreactivity suggested that many $\mathrm{Tbr}^{+}$cells project to contralateral medial deep nuclei via the hook bundle (Fig. 5A,B). To assess axon projections directly, we combined retrograde axon tracing from potential target nuclei with immunofluorescence to detect Tbr1.

One of the most robust efferent pathways from the DCN is the projection to

$\leftarrow$

protuberance (DLP) of the medial deep nuclei. Orientation of sagittal sections is dorsal top and rostral left; coronal sections are dorsal top and medial left. $A_{1}$, Cell group $A_{1}$ (Altman and Bayer, 1985a); (P, choroid plexus; (TZ, cortical transitory zone; D, dorsal; EGL, external granular layer; IC, inferior colliculus; IGL, internal granular layer; $M$, medial; PCL, Purkinje cell layer; $R$, rostral; RL, rhombic lip. Scale bar: (in $\boldsymbol{A}) \boldsymbol{A}-\boldsymbol{E}, 150$ $\mu \mathrm{m} ; \boldsymbol{F}-\boldsymbol{K}, 200 \mu \mathrm{m}$. 

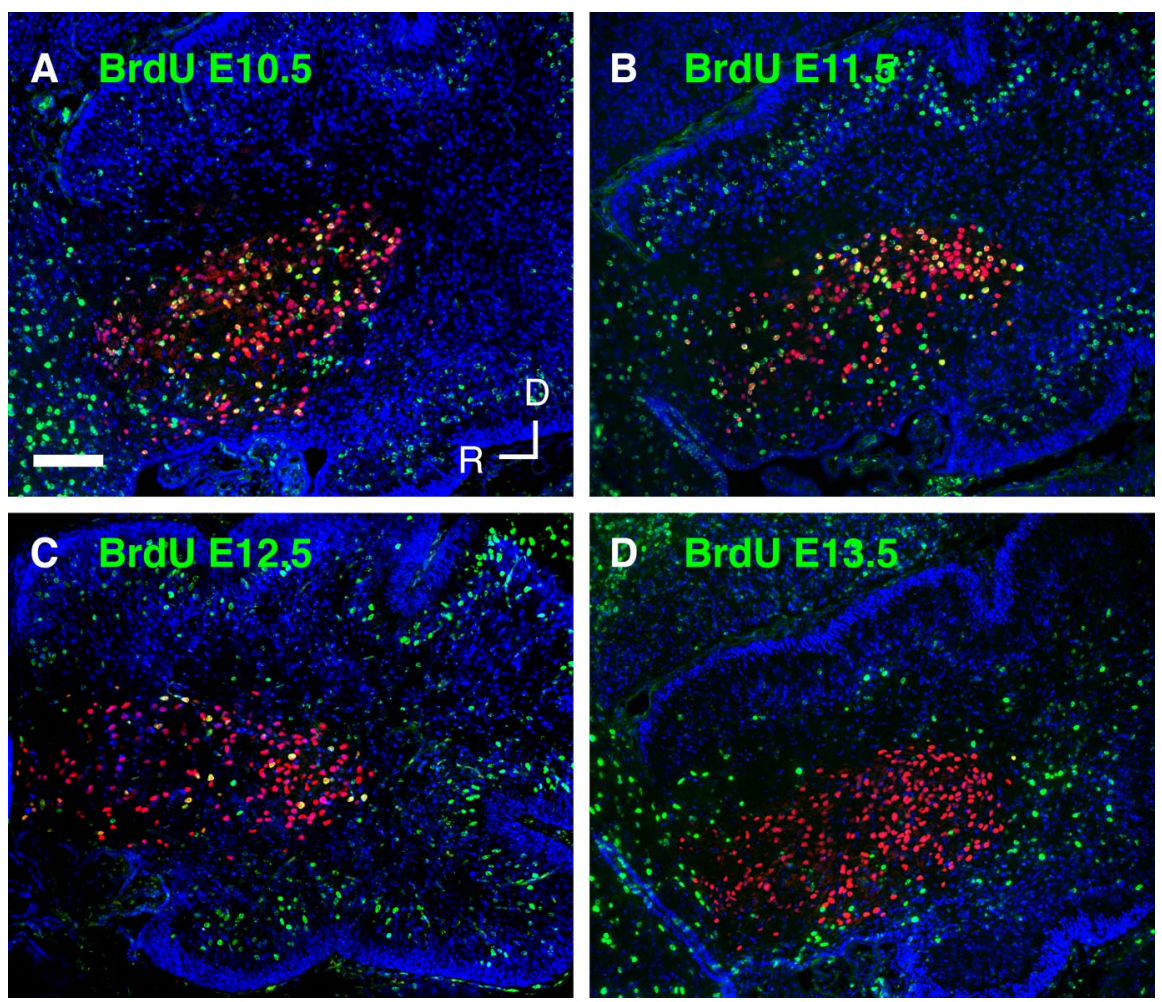

Figure 4. Birth dating of $\mathrm{Tbr}^{+}{ }^{+}$cells (red) in DCN. BrdU (green) was administered on E10.5 (A), E11.5 (B), E12.5 (C), or E13.5 (D) and studied on P0.5. Most Tbr1 ${ }^{+}$cells were born on E10.5-E12.5. Sagittal sections are dorsal (D) top and rostral (R) left. Scale bar, $100 \mu \mathrm{m}$.

contralateral red nuclei. This pathway was traced retrogradely by placing DiI in the red nucleus unilaterally in fixed neonatal (P0.5) brains. Remarkably, no retrogradely labeled neurons expressed Tbr1, although $\mathrm{Tbr}^{+}$cells and retrogradely DiI-labeled cells were mingled within the medial DCN (Fig. 6A). Instead, Tbr ${ }^{+}$ cells projected to other targets. The best correlation was with projections through the hook bundle, labeled retrogradely with DiI in the contralateral medial DCN (Fig. 6B); however, some cells labeled retrogradely through the hook bundle did not express Tbr1 (Fig. 6B). Partial correlations were also observed for projections to the ipsilateral vestibular nuclei (Fig. $6 C$ ) and to the spinal cord (Fig. $6 D, E$ ). In sum, Tbr $1^{+}$cells project to several target structures, most often the contralateral medial nucleus, but not to red nuclei.

\section{The NTZ forms appropriately in reeler mutant mice}

Reeler mutant mice have a severe cerebellar malformation caused by a deficiency of reelin protein, which guides the migrations of various cell types, including Purkinje cells (Rice and Curran, 2001). Because reelin ${ }^{+}$cells are scattered along the pathway from the rhombic lip to the NTZ (Fig. 1E,G) (Miyata et al., 1996), we considered the possibility that reeler mice might have a defect in the migration of cells to the NTZ through the subpial stream. Using Tbr 1 and Tbr2 as markers, we found that the NTZ in reeler mice developed in the appropriate position by E16.5 (Fig. 7 A, B). These results indicated that reelin is not required for rhombic lip cells to migrate through the subpial stream to the NTZ; however, subsequent DCN morphogenesis was abnormal in reeler mutant mice, because the shape of the medial DCN appeared distorted on P0.5 (Fig. 7C,D). This distortion was possibly a secondary effect of abnormal Purkinje cell migrations, as demonstrated by calbindin immunofluorescence (Fig. 7C,D).

\section{DCN are disorganized in Tbr1}

\section{mutant mice}

To investigate Tbr1 functions in DCN development, we studied Tbr1 null mutant mice. These mice have severe malformations of the olfactory bulb and cerebral cortex and die within 1-2 postnatal days because of poor feeding (Bulfone et al., 1998; Hevner et al., 2001). Because Tbr $1^{-1-}$ pups died soon after birth, our evaluation of the cerebellar phenotype was limited to embryonic and newborn periods.

Cresyl violet-stained sections revealed disorganization of the DCN in $\mathrm{Tbr}^{-1-}$ mutants, suggestive of a cell migration disorder (Fig. 8). In controls, the DCN had a compact, ribbon-like appearance (Fig. $8 A-D)$, but in $T b r 1^{-1-}$ mutants, DCN cells were irregularly dispersed, and boundaries between DCN and white matter were poorly defined (Fig. $8 E-H$ ). The dorsolateral protuberance of the medial nucleus (Voogd, 1995) was prominent in controls (Fig. $8 \mathrm{~A}, \mathrm{C}$ ) but was not recognizable in Tbr $1^{-1-}$ mutants (Fig. $8 E, G$ ). The interposed and lateral nuclei also appeared disorganized but were not as severely affected as medial nuclei. The cerebellar cortex showed no obvious abnormalities in $\mathrm{Tbr1}^{-1-}$ mutants.

Despite the abnormal histology of the DCN, there was no apparent neuronal loss. NeuN immunohistochemistry and BrdU birth dating showed no decrease in the number of early-born neurons in $\mathrm{Tbr} 1^{-1-}$ mutants versus control DCN. Also, terminal deoxynucleotidyl transferase-mediated biotinylated UTP nick end labeling on E14.5, E17.5, and P0.5 showed no increase of apoptosis (data not shown). Reelin expression was not altered in the NTZ or other cerebellar structures of $\mathrm{Tbr1} 1^{-1-}$ mutants (supplemental Fig. 1, available at www.jneurosci.org as supplemental material). These results indicate that Tbr1 plays a role in DCN morphogenesis, but additional studies will be necessary to define this role more clearly.

\section{Axon pathways in Tbr1 mutant cerebellum}

Tbr1 mutant mice have severe abnormalities of axonal pathway development in the forebrain (Hevner et al., 2001, 2002). Thus, we suspected that axon pathways might also develop abnormally in the cerebellum. To investigate this possibility, we labeled afferent and efferent connections of the DCN with specific molecular markers and by anterograde and retrograde labeling with DiI (Fig. 9). Because little is known about the early development of DCN projections, our studies in controls also provided important baseline information.

Molecular markers revealed axon pathway development as well as aspects of DCN neuronal differentiation. The hook bundle, a major output tract of the medial DCN, expressed appropriate markers in $T b r 1^{-1-}$ mutants, as shown by calretinin (Fig. $9 A-D$ ) and VGLUT2 immunoreactivity (Fig. 9E,F). The superior cerebellar peduncle, a major output pathway from the DCN, also developed appropriately on the basis of VGLUT2 immunoreactivity (Fig. 9G,H). Intact VGLUT2 immunoreactivity suggested that glutamatergic differentiation was preserved in 

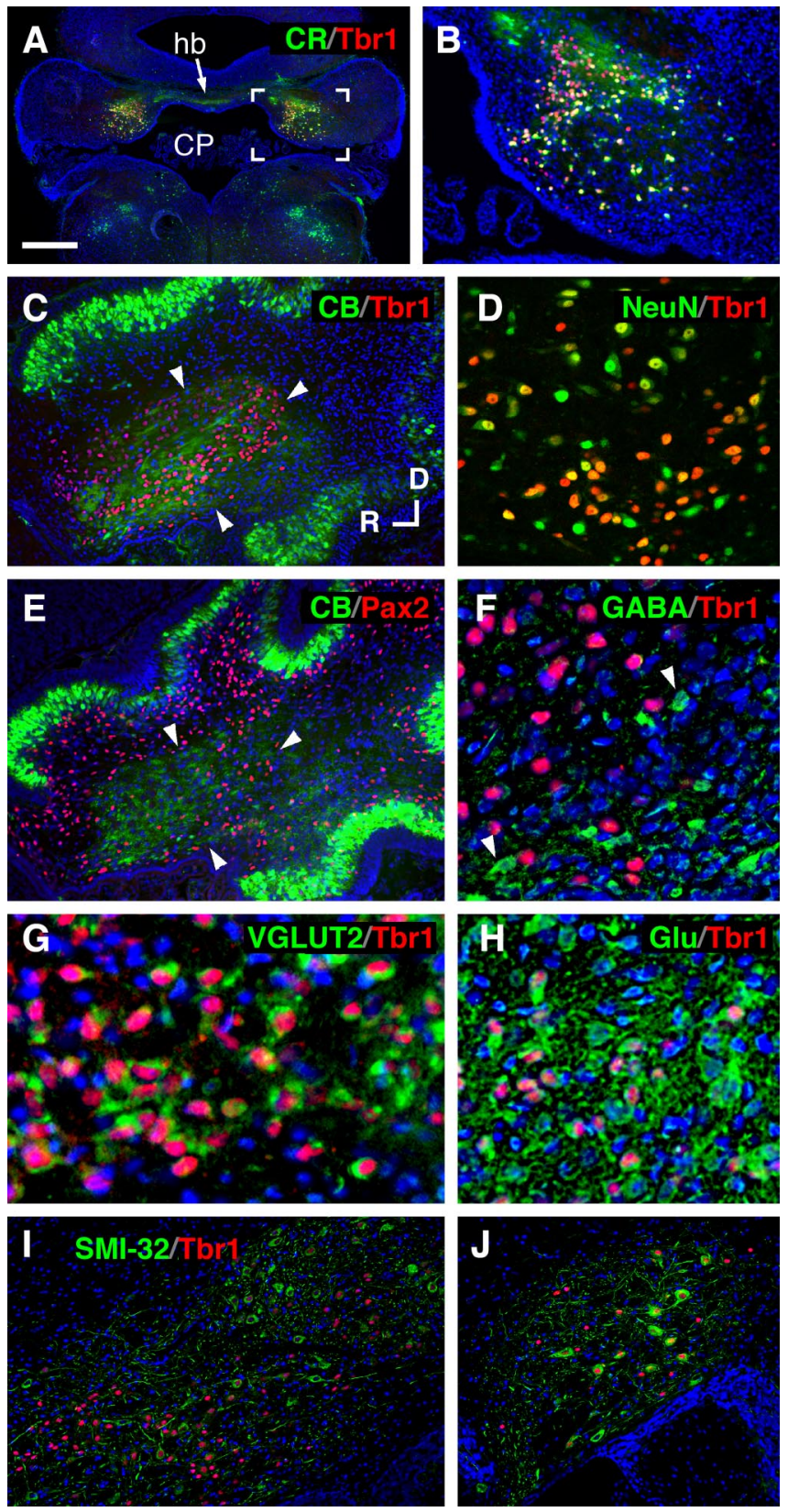

Figure 5. $\quad \mathrm{Tbr}^{+} \mathrm{DCN}$ cells are glutamatergic projection neurons. $A, B, \mathrm{Tbr} 1$ (red) and calretinin (green), coronal section (E17.5). The bracketed area in $\boldsymbol{A}$ is enlarged in $\boldsymbol{B}$. Most calreti$\mathrm{nin}^{+}$cells expressed Tbr1 and sent axons across the midline through the hook bundle (hb). $C$, Tbr1 (red) and calbindin (green); sagittal section; P0.5. Calbindin ${ }^{+}$Purkinje cell axons entered the DCN (arrowheads) and surrounded Tbr ${ }^{+}{ }^{+}$cells. D, Tbr1 (red) and NeuN (green); P0.5. Most $\mathrm{Tbr}^{+}{ }^{+}$cells were NeuN ${ }^{+}$. E, Pax2 (red) and calbindin (green); sagittal section; P0.5. Pax2 ${ }^{+}$ GABAergic interneurons largely avoided the DCN (arrowheads). $\boldsymbol{F}$, Tbr 1 (red) and GABA (green); P0.5. GABA ${ }^{+}$interneurons (arrowheads) did not express Tbr1. G, Tbr1 (red) and VGLUT2 mRNA (green); P0.5. Virtually all Tbr ${ }^{+}$cells expressed VGLUT2. $\boldsymbol{H}$, Tbr1 (red) and glutamate (green); P0.5. A subset of glutamatergic neurons expressed Tbr1. I, J, Tbr1 (red) and SMI-32 (green); P21 (I) and P201 (J). Tbr $1^{+}-\mathrm{SMI}-32^{+}$, Tbr1 ${ }^{+}-\mathrm{SMI}-32^{-}$, and Tbr1 ${ }^{-}-\mathrm{SMI}-32^{+}$cells were all observed. CB, Calbindin; $C P$, Choroid plexus; $C R$, calretinin. Scale bar: (in $A) A, 400 \mu \mathrm{m} ; \boldsymbol{B}, C, E$, $\boldsymbol{I}, J, 100 \mu \mathrm{m} ; \boldsymbol{D}, \boldsymbol{H}, 50 \mu \mathrm{m} ; \boldsymbol{F}, \mathbf{G}, 25 \mu \mathrm{m}$.

Tbr $1^{-1-}$ mutants. This point was confirmed by VGLUT2 in situ hybridization (data not shown). Afferent innervation of the DCN from Purkinje cells was not defective, as demonstrated by calbindin immunoreactivity (Fig. 9I,J).

DiI tracing likewise showed no early defects of DCN axon
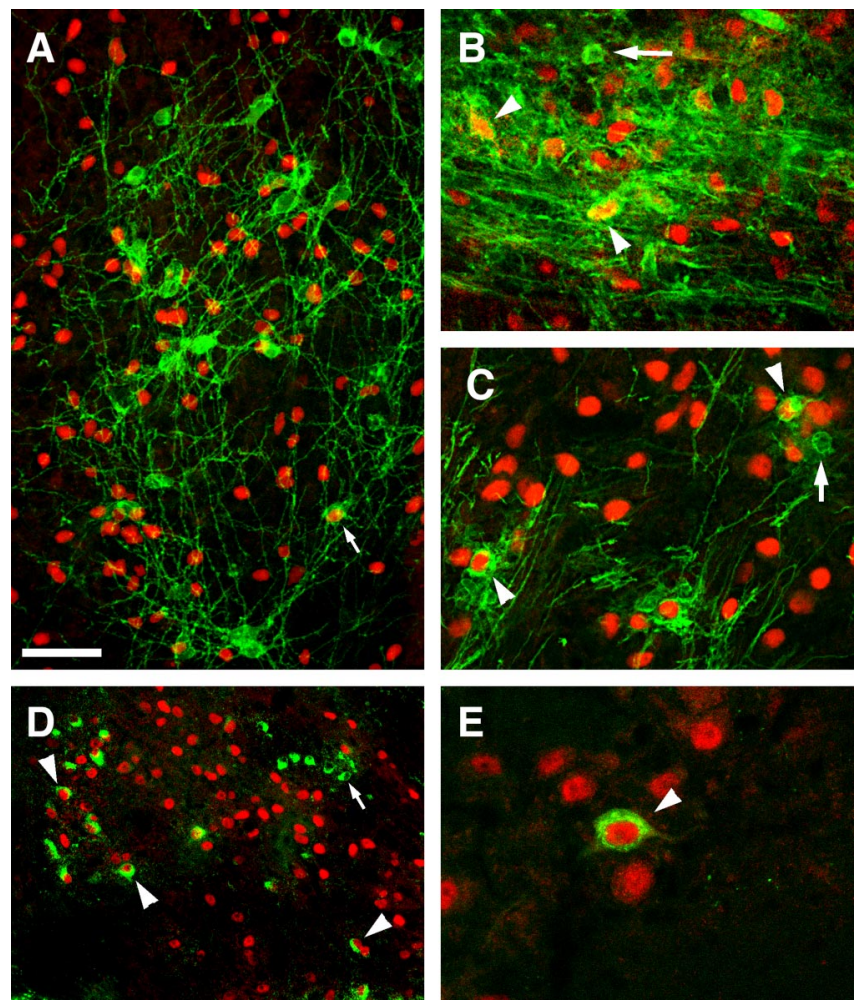

Figure 6. Axon projections of Tbr $1^{+}$neurons. Expression of Tbr1 (red) was compared with axon projections and labeled retrogradely with Dil or CTB-A488 (green). For experiments with Dil, colors were reversed with Photoshop so that Tbr1 could be shown as red fluorescence in all panels. A, Dil labeling from contralateral red nucleus; $\mathrm{P} 0.5$. № $\mathrm{Tbr} 1{ }^{+}$cells projected to the red nuclei. One cell in this collapsed confocal $z$-series appeared to be double labeled (arrow), but the retrogradely labeled cell and the $\mathrm{Tbr}^{+}{ }^{+}$cell were actually in different $z$-axis planes. $\boldsymbol{B}$, Dil labeling of hook bundle axons from the contralateral medial DCN; P0.5. Many retrogradely labeled cells expressed Tbr1 (arrowheads), but some did not (arrow). C, Dil labeling from the ipsilateral lateral vestibular nucleus; P0.5. Among retrogradely labeled cells, some expressed Tbr1 (arrowheads), and some did not (arrow). D, (TB-A488 labeling from the cervical spinal cord; P7-P10. Some retrogradely labeled cells expressed Tbr1 (arrowheads), and some did not (arrow).E, CTB-A488 labeling from the cervical spinal cord; P17-P20. Scale bar: (in A) A, $50 \mu \mathrm{m}$; $B, C, E, 30 \mu \mathrm{m} ; D, 80 \mu \mathrm{m}$.

pathways in $\mathrm{Tbr} 1^{-1-}$ mutants. Unilateral placement of DiI in the medial DCN labeled the hook bundle, the uncinate fasciculus, and small axon bundles into the vestibular nuclei in controls (Fig. $9 \mathrm{~K}-\mathrm{M}$ ) as well as in $\mathrm{Tbr} \mathrm{1}^{-1-}$ mutants (Fig. $9 \mathrm{~N}-\mathrm{P}$ ). Small projections to the red nuclei were also labeled from the medial DCN (data not shown). DiI crystals in the lateral and interposed deep nuclei labeled robust pathways through the superior cerebellar peduncle to the red nuclei and the pons, which were identical in controls and in Tbr1 $1^{-1-}$ mutants (Fig. 9Q,R). In sum, Tbr1 deficiency had no apparent adverse effects on the development of afferent or efferent connections of the DCN through P0.5.

\section{Discussion}

DCN projection neurons originate from the rhombic lip

It had been thought previously that DCN projection neurons are produced mainly in the cerebellar VZ from the same progenitor cells that produce Purkinje cells (for reviews, see Goldowitz and Hamre, 1998; Wang and Zoghbi, 2001). The possibility that some DCN neurons originate from the rhombic lip was raised by Korneliussen (Korneliussen and Jansen, 1965; Korneliussen, 1967), but this idea gained little support until recently. In the past few years, clonal lineage analysis has shown that DCN neurons may be produced from separate progenitors than other cerebellar 

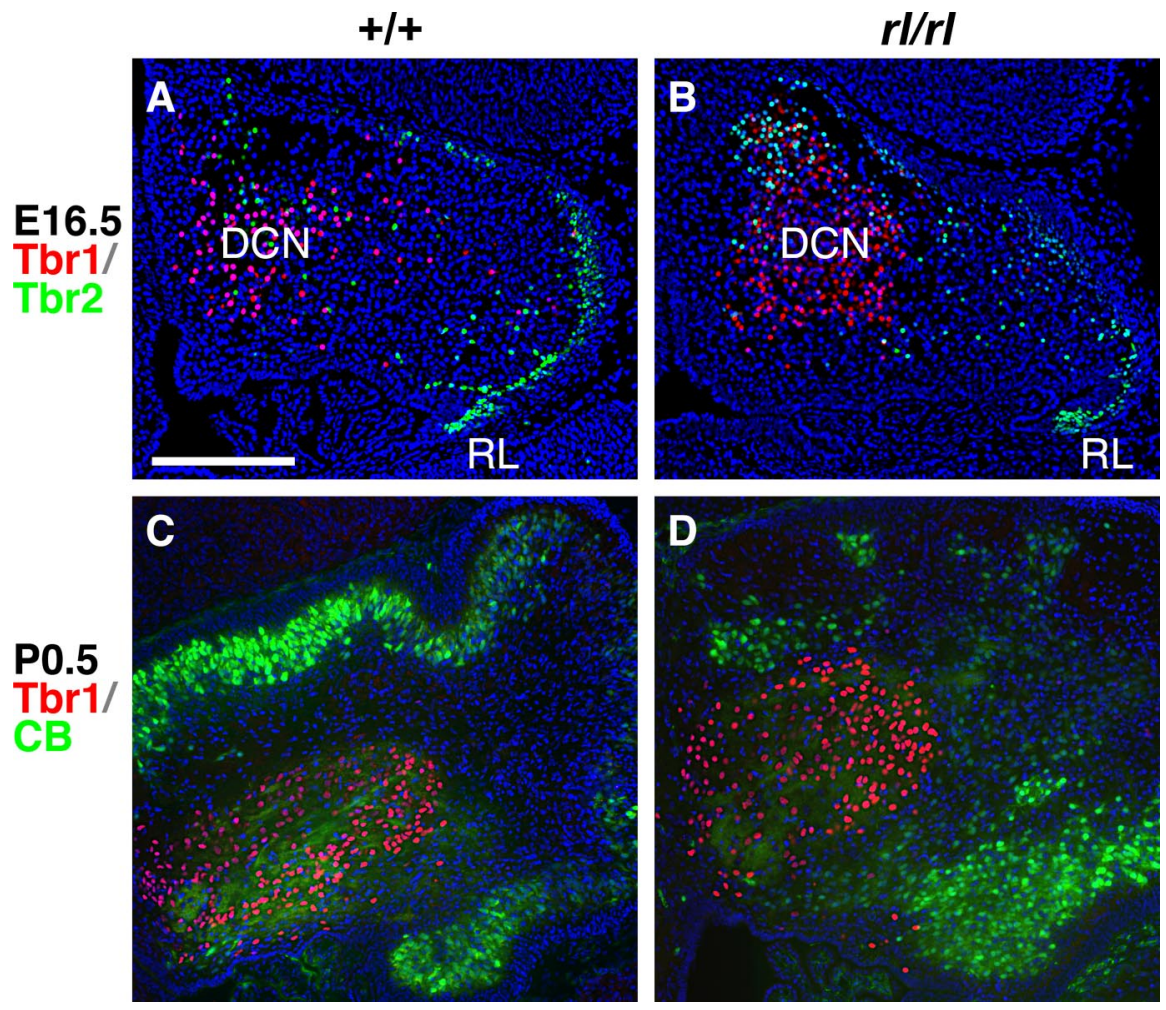

Figure 7. DCN development in reeler mutants. $\boldsymbol{A}, \boldsymbol{B}, \mathrm{Tbr} 1$ (red) and Tbr2 (green) expression in control $(\boldsymbol{A})$ and reeler $(\boldsymbol{B})$ E16.5 cerebellum. Tbr ${ }^{+}$cells and Tbr2 ${ }^{+}$cells were abundant in the DCN of reeler mutants as in controls, indicating that cells migrated appropriately from the rhombic lip (RL) to the NTZ. Tbr2 ${ }^{+}$cells in the rhombic lip on E16.5 are unipolar brush cells and their progenitors (C. Englund and R. F. Hevner, unpublished observations). C, D, Tbr1 (red) and calbindin (green) expression in control $(\boldsymbol{C})$ and reeler mutant (D) P0.5 cerebellum. The shape of the DCN, as indicated by Tbr ${ }^{+}$cells, was distorted because of (presumably) abnormal migrations of calbindin ${ }^{+}$Purkinje cells. Sagittal sections are counterstained with DAPI (blue). Orientation is dorsal top and rostral left. Scale bar, $100 \mu \mathrm{m}$.
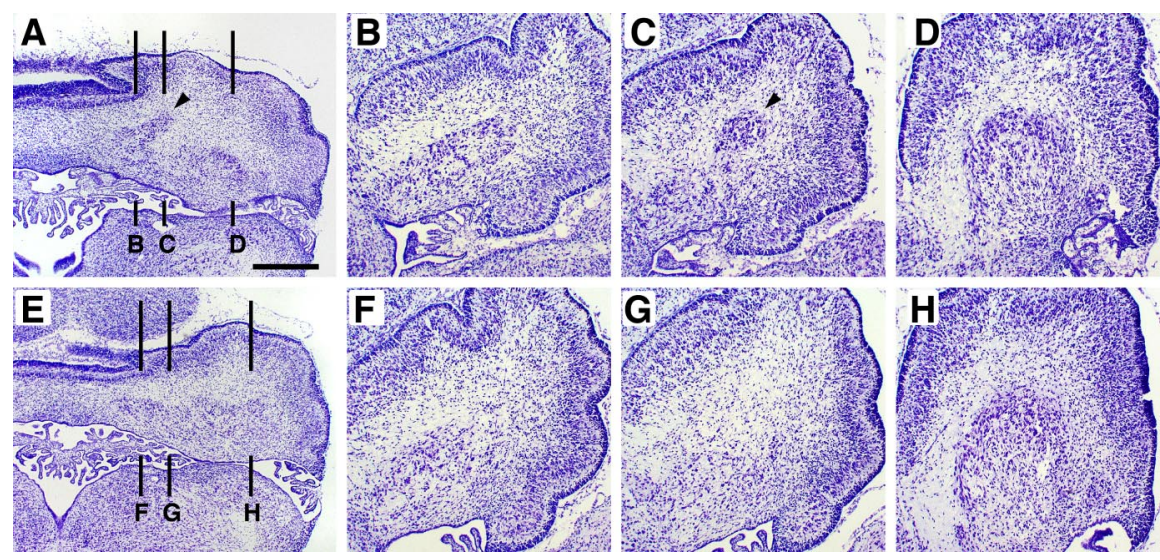

Figure 8. DCN malformation in Tbr1 mutant P0.5 cerebellum. $\boldsymbol{A}-\boldsymbol{D}$, Coronal $(\boldsymbol{A})$ and sagittal $(\boldsymbol{B}-\boldsymbol{D})$ sections through normal cerebellum. Lines in $\boldsymbol{A}$ indicate levels of sections in $\boldsymbol{B}-\boldsymbol{D}$. The normal $\mathbf{D C N}$ had smooth, ribbon-like contours, with a prominent dorsolateral protuberance $(\boldsymbol{A}, \boldsymbol{C}$, arrowheads) from the medial nucleus. $\boldsymbol{E}-\boldsymbol{H}$, Coronal $(\boldsymbol{E})$ and sagittal $(\boldsymbol{F}-\boldsymbol{H})$ sections through the $\mathrm{Tbr} 1$ mutant cerebellum. Lines in $\boldsymbol{E}$ indicate levels of sections in $\boldsymbol{F} \boldsymbol{H}$. The Tbr1 mutant DCN had irregular contours and appeared disorganized. The dorsolateral protuberance did not form recognizably (compare $\boldsymbol{C}, \boldsymbol{G}$ ). Cresyl violet-stained coronal sections are oriented dorsal top and lateral right; sagittal sections are oriented dorsal top and rostral left. Scale bar: (in $\boldsymbol{A}) \boldsymbol{A}, \boldsymbol{E}, 400 \mu \mathrm{m} ; \boldsymbol{B}-\boldsymbol{D}$, $F-H, 200 \mu \mathrm{m}$.

neuron types, such as Purkinje cells (Mathis and Nicolas, 2003). Also, Jensen et al. (2004) described a migration of Math ${ }^{+}$cells from the rhombic lip to the NTZ, although the implication for DCN formation was unclear. Most recently, genetic lineage tracing suggested that most DCN projection neurons, including
$\mathrm{Tbr}^{+}$cells, are produced from Math $1^{+}$ progenitors in the rhombic lip (Machold and Fishell, 2005; Wang et al., 2005).

In the present study, two lines of evidence indicated that many DCN neurons originate from the rhombic lip. First, the expression patterns of Pax6, Tbr2, and Tbr1 delineated a subpial migration pathway or stream from the rhombic lip to the NTZ (Fig. 1). The continuity of this pathway was indicated by coexpression of Pax6 with Tbr2 and Tbr1 at the transition from the subpial stream to the NTZ. The origin of the subpial stream was inferred from Pax6 expression, because Pax6 is a marker of the rhombic lip and cells migrating away from it (Engelkamp et al., 1999). Second, organotypic slice cultures provided direct evidence that the rhombic lip is necessary and sufficient to supply cell migration into the subpial stream and the NTZ (Fig. 2). The subpial stream observed in the present study appears to correspond to part of the "rostral rhombic-lip migratory stream" described by Wang et al. (2005).

The present study also suggested that reelin ${ }^{+}$cells in the subpial stream and the NTZ originate from the rhombic lip. Reelin $^{+}$cells expressed Pax6 (Fig. 1F), and rhombic lip ablation caused partial depletion of reelin ${ }^{+}$cells in organotypic slice cultures (data not shown). Miyata et al. (1996) reported that reelin ${ }^{+}$cells along the subpial surface of the E13 mouse cerebellum express Zic1, a zinc finger transcription factor. Notably, Zicl is expressed mainly in the rhombic lip and its derivatives (Aruga et al., 1994, 1998; Lin et al., 2001). The function of reelin in the subpial stream and the NTZ may be to regulate Purkinje cell migrations (Rice and Curran, 2001). In the present study, we found that reelin is not required for cell migration from the rhombic lip through the subpial stream to the NTZ (Fig. 7A,B).

\section{A model for cerebellar neurogenesis: compartmentalization of glutamatergic and GABAergic neuron progenitors} In the embryonic brain, progenitor cells are organized into molecularly defined compartments that confer patterning information during neurogenesis and thereby regulate key aspects of cell fate (Wurst and Bally-Cuif, 2001; Schuurmans and Guillemot, 2002). In the cerebellum, the cerebellar VZ and the rhombic lip have been recognized as distinct progenitor compartments on the basis of morphological and molecular criteria (Engelkamp et al., 1999; Wang and Zoghbi, 2001; Wingate, 2001; Hoshino et al., 2005; Wang et al., 2005). Interestingly, our Pax6 protein expression data suggest that the rhombic lip progenitor compartment 
may actually be slightly larger than the morphologically defined rhombic lip (Figs. 1A, 2B).

The finding that DCN projection neurons come from the rhombic lip has significant implications for understanding overall cerebellar neurogenesis. The cerebellum contains five main classes of neurons, of which two are GABAergic (Purkinje cells and inhibitory interneurons) and three are glutamatergic (DCN projection neurons, granule neurons, and unipolar brush cells). Morphological and genetic approaches both suggest that all GABAergic types are produced from the cerebellar VZ (Zhang and Goldman, 1996; Goldowitz and Hamre, 1998; Maricich and Herrup, 1999; Wang and Zoghbi, 2001; Hoshino et al., 2005). Among glutamatergic types, DCN projection neurons come from the rhombic lip (Machold and Fishell, 2005; Wang et al., 2005; present study). Granule cells are produced from the external granular layer, which is a rhombic lip derivative (Ben-Arie et al., 1997; Wingate, 2001; Machold and Fishell, 2005). The origins of unipolar brush cells have been difficult to discern (Sekerková et al., 2004; Ilijic et al., 2005); however, new data from our laboratory suggest that unipolar brush cells are likewise produced from the rhombic lip (Englund and Hevner, unpublished observations). Together, these findings suggests that most or all glutamatergic neurons in the cerebellum originate from the rhombic lip.

Overall, the rhombic lip and cerebellar VZ thus appear to be specialized for the production of glutamatergic and GABAergic cerebellar neurons, respectively (supplemental Fig. 2, available at www.jneurosci.org as supplemental material). This hypothesis resembles neurogenesis in the telencephalon, where glutamatergic neurons are produced in the cortical VZ and GABAergic neurons are produced in basal forebrain regions (Schuurmans and Guillemot, 2002). Interestingly, glutamatergic neurons in the cerebellum, as in the telencephalon, are produced in the embryologically more dorsal progenitor compartment (closer to the roof plate); however, glutamatergic neurons may not be the only neurotransmitter type produced in the cerebellar rhombic lip, because mesopontine cholinergic neurons evidently come from this progenitor compartment as well (Machold and Fishell, 2005).

Pax6, Tbr2, and Tbr1: a transcription factor sequence for glutamatergic neurogenesis in the DCN and the cerebral cortex

In the embryonic cerebral cortex, Pax6, Tbr2, and Tbr1 are expressed sequentially in radial glia, intermediate progenitor cells, and postmitotic neurons (Englund et al., 2005). Remarkably, this
Tbr1 -1-
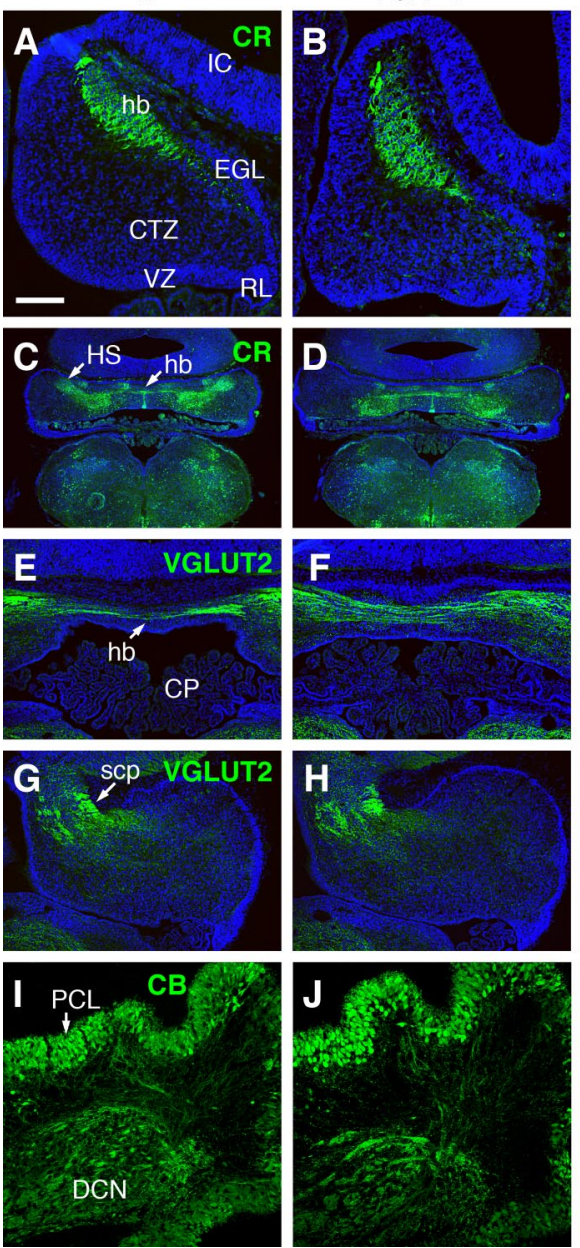
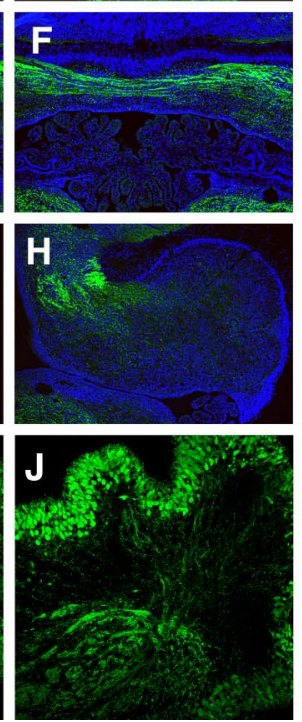

$+l$
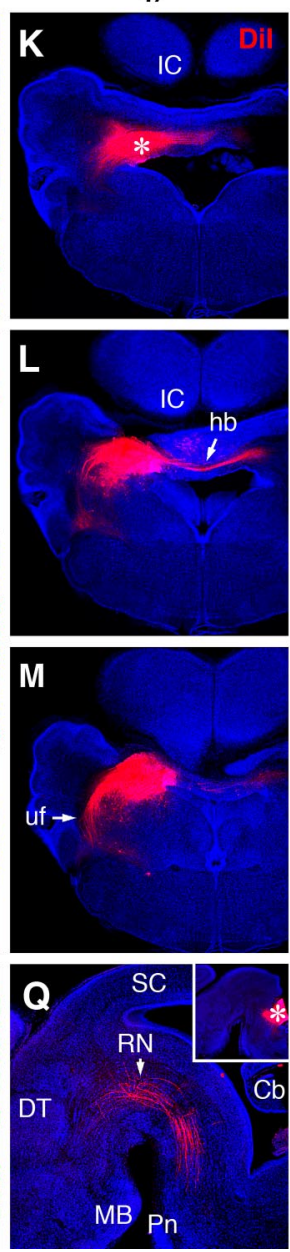

Tbr1-l-
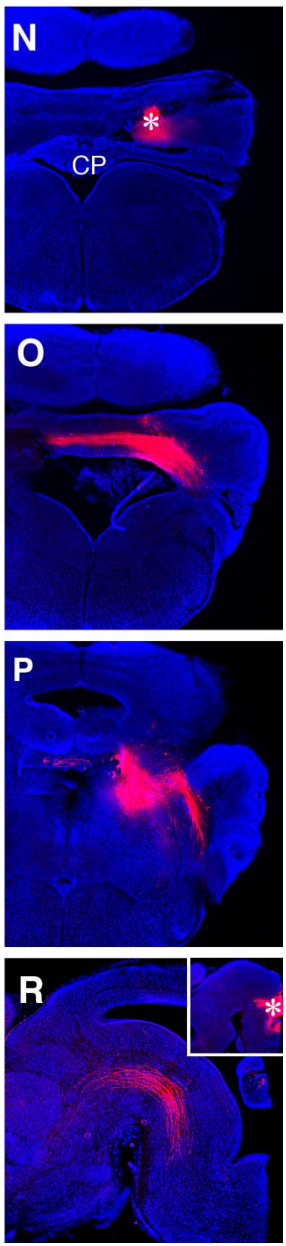

Figure 9. DCN axon connections showed no obvious defects in $T b r 1^{-1-}$ brains $(B, D, F, H, J, N-P, R)$. Littermate controls are E17.5 coronal sections $(\boldsymbol{C}, \boldsymbol{D})$. Calretinin was expressed in the medial DCN and the hook bundle $(\mathrm{hb})$ of Tbr1 mutants, as in controls. The calretinin ${ }^{+}$hotspot (HS) (Abbott and Jacobowitz, 1995) labeled in E17.5 control tissue (C) was also present in Tbr1 mutants ot shown as prominently in $\boldsymbol{D}$ because of the slightly different plane of section. $\boldsymbol{E}-\boldsymbol{H}, \mathrm{VGLUT2}$ immunoreactivity in E17.5 coronal sections $(\boldsymbol{E}, \boldsymbol{F})$ and E17.5 sagittal sections $(\boldsymbol{G}, \boldsymbol{H})$. The hook bundle and superior cerebellar peduncle (scp) expressed GLUT2 appropriately in Tbr1 mutants. I, J, Calbindin immunofluorescence; P0.5; sagittal sections. Calbindin ${ }^{+}$axons extended caudal to rostral series of coronal sections through $\mathbf{P} 0.5$ control $(\boldsymbol{K}-\mathbf{M})$ and $T b r 1$ mutant $(\boldsymbol{N}-\boldsymbol{P})$ brains. The Dil crystal injection sites 政 mutant $(\boldsymbol{R})$ brains. Insets show the Dil crystal injection sites (asterisks) in more lateral sections through the same brains. Projec all panels (except $I, J$ ) is DAPI. Cb, Cerebellum; (P, choroid plexus; DT, dorsal thalamus; EGL, external granular layer; IC, inferior colliculus; MB, mammillary body; SC, superior colliculus. Scale bar: (in $\boldsymbol{A}) \boldsymbol{A}, \boldsymbol{B}, \boldsymbol{I}, \boldsymbol{J}, 100 \mu \mathrm{m} ; \boldsymbol{C}, \boldsymbol{D}, \boldsymbol{K}-\boldsymbol{R}, 500 \mu \mathrm{m} ; \boldsymbol{E}-\boldsymbol{H}, 200 \mu \mathrm{m}$.

same transcription factor sequence is recapitulated in the neurogenesis of DCN projection neurons. The precise meaning of this transcription factor sequence is unclear, but it is tempting to speculate that it may be linked to key phenotypes in glutamatergic neurogenesis. Pax6 regulates cell migration in both the cerebellum and the cerebral cortex (Caric et al., 1997; Engelkamp et al., 1999). Moreover, Pax6 also specifies neuronal fate and glutamatergic fate in the cerebral cortex (Heins et al., 2002; Schuurmans et al., 2004). Tbr2 functions in brain development are unknown. Inactivation of the Tbr2 gene causes early embryonic lethality, before the start of brain development (Russ et al., 2000). Tbr2 is expressed in several glutamatergic lineages but has not yet been linked to any GABAergic lineages (Englund et al., 2005; present study; Englund and Hevner, unpublished observations). Tbr1 
appears to be expressed exclusively in glutamatergic lineages (Bulfone et al., 1998; Hevner et al., 2001; Englund et al., 2005; present study). Functionally, Tbr1 regulates reelin expression and axon pathfinding in the cerebral cortex (Hevner et al., 2001, 2002) but appears to play a more limited role in the cerebellum. In the present study, we found that Tbrl deficiency caused abnormal DCN morphogenesis (Fig. 8) but no apparent defects of reelin expression (supplemental Fig. 1, available at www.jneurosci.org as supplemental material), glutamatergic differentiation, or initial axon pathfinding (Fig. 9).

Other transcription factors expressed in the DCN during development include Otx3-Dmbx1 (Kimura et al., 2005), and Brn1 and Brn2 (Fig. 3J,K) (Sugitani et al., 2002). Mice deficient in Otx3-Dmbxl have reduced numbers of Dmbxl promoterexpressing cells in the DCN, suggesting a possible defect of neurogenesis (Ohtoshi and Behringer, 2004). Brn1 and Brn2 are necessary for the development of cerebellar folia (Sugitani et al., 2002).

\section{Development of DCN efferent axon pathways}

Our results in the present study suggest that DCN axon pathways appear relatively early in cerebellar development. The hook bundle was established by E14.5 (Fig. 9A,B) and exhibited evidence of glutamatergic function (VGLUT2 immunoreactivity) by E17.5 (Fig. 9G,H). Efferent fibers through the superior cerebellar peduncle reached the red nuclei and basal pons by E17.5 (Fig. $9 Q, R$ ), and likewise demonstrated VGLUT2 immunoreactivity in the superior cerebellar peduncle by E17.5 (Fig. 9G,H). These findings indicate that some DCN efferent pathways develop axon projections before DCN cell migration is complete. The efferent pathways also exhibited VGLUT2 expression, an essential component of glutamatergic neurotransmission, earlier in development than thought previously (Boulland et al., 2004). Although Tbr1 is apparently not required for the initial development of DCN axon pathways, a later role cannot be excluded, because Tbr1 mutants survived only until P0.5. The mechanisms that control DCN axon guidance, like those that control DCN cell migration, will be important subjects for future study.

\section{References}

Abbott LC, Jacobowitz DM (1995) Development of calretininimmunoreactive unipolar brush-like cells and an afferent pathway to the embryonic and early postnatal mouse cerebellum. Anat Embryol 191:541-559.

Altman J, Bayer SA (1985a) Embryonic development of the rat cerebellum. I. Delineation of the cerebellar primordium and early cell movements. J Comp Neurol 231:1-26.

Altman J, Bayer SA (1985b) Embryonic development of the rat cerebellum. II. Translocation and regional distribution of the deep neurons. J Comp Neurol 231:27-41.

Anderson SA, Eisenstat DD, Shi L, Rubenstein JLR (1997) Interneuron migration from basal forebrain to neocortex: dependence on $D l x$ genes. Science 278:474-476.

Aruga J, Yokota N, Hashimoto M, Furuichi T, Fukuda M, Mikoshiba K (1994) A novel zinc finger protein, Zic, is involved in neurogenesis, especially in the cell lineage of cerebellar granule cells. J Neurochem 63:1880-1890.

Aruga J, Minowa O, Yaginuma H, Kuno J, Nagai T, Noda T, Mikoshiba K (1998) Mouse Zicl is involved in cerebellar development. J Neurosci 18:284-293.

Ben-Arie N, Bellen HJ, Armstrong DL, McCall AE, Gordadze PR, Guo Q, Matzuk MM, Zoghbi HY (1997) Math1 is essential for genesis of cerebellar granule neurons. Nature 390:169-172.

Boulland J-L, Qureshi T, Seal RP, Rafiki A, Gundersen V, Bergersen LH, Fremeau Jr RT, Edwards RH, Storm-Mathisen J, Chaudhry FA (2004) Expression of the vesicular glutamate transporters during development indicates the widespread corelease of multiple neurotransmitters. J Comp Neurol 480:264-280.

Bulfone A, Smiga SM, Shimamura K, Peterson A, Puelles L, Rubenstein JLR (1995) T-Brain-1: a homolog of Brachyury whose expression defines molecularly distinct domains within the cerebral cortex. Neuron 15:63-78.

Bulfone A, Wang F, Hevner R, Anderson S, Cutforth T, Chen S, Meneses J, Pederson R, Axel R, Rubenstein JLR (1998) An olfactory sensory map develops in the absence of normal projection neurons or GABAergic interneurons. Neuron 21:1273-1282.

Bulfone A, Martinez S, Marigo V, Campanella M, Basile A, Quaderi N, Gattuso C, Rubenstein JLR, Ballabio A (1999) Expression pattern of the Tbr2 (Eomesodermin) gene during mouse and chick brain development. Mech Dev 84:133-138.

Caric D, Gooday D, Hill RE, McConnell SK, Price DJ (1997) Determination of the migratory capacity of embryonic cortical cells lacking the transcription factor Pax-6. Development 124:5087-5096.

Engelkamp D, Rashbass P, Seawright A, van Heyningen V (1999) Role of Pax6 in development of the cerebellar system. Development 126:3585-3596.

Englund C, Fink A, Lau C, Pham D, Daza RA, Bulfone A, Kowalczyk T, Hevner RF (2005) Pax6, Tbr2, and Tbr1 are expressed sequentially by radial glia, interposed progenitor cells, and postmitotic neurons in developing neocortex. J Neurosci 25:247-251.

Fremeau RT, Troyer MD, Pahner I, Nygaard GO, Tran CH, Reimer RJ, Bellocchio EE, Fortin D, Storm-Mathisen J, Edwards RH (2001) The expression of vesicular glutamate transporters defines two classes of excitatory synapse. Neuron 31:247-260.

Goffinet A (1983) The embryonic development of the cerebellum in normal and reeler mutant mice. Anat Embryol 168:73-86.

Goldowitz D, Hamre K (1998) The cells and molecules that make a cerebellum. Trends Neurosci 21:375-382.

Heins N, Malatesta P, Cecconi F, Nakafuku M, Tucker KL, Hack MA, Chapouton P, Barde Y-A, Götz M (2002) Glial cells generate neurons: the role of the transcription factor Pax6. Nat Neurosci 5:308-315.

Hevner RF, Shi L, Justice N, Hsueh Y-P, Sheng M, Smiga S, Bulfone A, Goffinet AM, Campagnoni AT, Rubenstein JLR (2001) Tbr1 regulates differentiation of the preplate and layer 6. Neuron 29:353-366.

Hevner RF, Miyashita-Lin E, Rubenstein JLR (2002) Cortical and thalamic axon pathfinding defects in Tbr1, Gbx2, and Pax6 mutant mice: evidence that cortical and thalamic axons interact and guide each other. J Comp Neurol 447:8-17.

Hevner RF, Daza RAM, Rubenstein JLR, Stunnenberg H, Olavarria JF, Englund C (2003) Beyond laminar fate: toward a molecular classification of cortical projection/pyramidal neurons. Dev Neurosci 25:139-151.

Hevner RF, Daza RAM, Englund C, Kohtz J, Fink A (2004) Postnatal shifts of interneuron position in the neocortex of normal and reeler mice: evidence for inward radial migration. Neuroscience 124:605-618.

Hoshino M, Nakamura S, Mori K, Kawauchi T, Terao M, Nishimura YV, Fukuda A, Fuse T, Matsuo N, Sone M, Watanabe M, Bito H, Terashima T, Wright CVE, Kawaguchi Y, Kakao K, Nabeshima Y (2005) Ptfla, a bHLH transcriptional gene, defines GABAergic neuronal fates in cerebellum. Neuron 47:201-213.

Ilijic E, Guidotti A, Mugnaini E (2005) Moving up or moving down? Malpositioned cerebellar unipolar brush cells in reeler mouse. Neuroscience 136:633-647.

Jensen P, Smeyne R, Goldowitz D (2004) Analysis of cerebellar development in math1 null embryos and chimeras. J Neurosci 24:2202-2211.

Kalinichenko SG, Okhotin VE (2005) Unipolar brush cells: a new type of excitatory interneuron in the cerebellar cortex and cochlear nuclei of the brainstem. Neurosci Behav Physiol 35:21-36.

Kimura K, Miki T, Shibasaki T, Zhang Y, Ogawa M, Saisho H, Okuno M, Iwanaga T, Seino S (2005) Functional analysis of transcriptional repressor Otx3/Dmbx1. FEBS Lett 579:2926-2932.

Korneliussen HK (1967) Cerebellar corticogenesis in cetacea, with special reference to regional variations. J Hinforsch 9:151-185.

Korneliussen HK, Jansen J (1965) On the early development and homology of the central cerebellar nuclei in cetacea. J Hirnforsch 8:47-56.

Lin JC, Cai L, Cepko CL (2001) The external granule layer of the developing chick cerebellum generates granule cells and cells of the isthmus and rostral hindbrain. J Neurosci 21:159-168.

Machold R, Fishell G (2005) Math1 is expressed in temporally discrete pools of cerebellar rhombic-lip neural progenitors. Neuron 48:17-24. 
Maricich SM, Herrup K (1999) Pax-2 expression defines a subset of GABAergic interneurons and their precursors in the developing murine cerebellum. J Neurobiol 41:281-294.

Mathis L, Nicolas J-F (2003) Progressive restriction of cell fates in relation to neuroepithelial cell mingling in the mouse cerebellum. Dev Biol 258:20-31.

Miale IL, Sidman RL (1961) An autoradiographic analysis of histogenesis in the mouse cerebellum. Exp Neurol 4:277-296.

Miyata T, Nakajima K, Aruga J, Takahashi S, Ikenaka K, Mikoshiba K, Ogawa M (1996) Distribution of a reeler gene-related antigen in the developing cerebellum: an immunohistochemical study with an allogeneic antibody CR-50 on normal and reeler mice. J Comp Neurol 372:215-228.

Ohtoshi A, Behringer RR (2004) Neonatal lethality, dwarfism, and abnormal brain development in Dmbxl mutant mice. Mol Cell Biol 24:7548-7558.

Pratt T, Sharp L, Nichols J, Price DJ, Mason JO (2000) Embryonic stem cells and transgenic mice ubiquitously expressing a tau-tagged green fluorescent protein. Dev Biol 228:19-28.

Rice DS, Curran T (2001) Role of the reelin signaling pathway in central nervous system development. Annu Rev Neurosci 24:1005-1039.

Russ AP, Wattler S, Colledge WH, Aparicio SAJR, Carlton MBL, Pearce JJ, Barton SC, Surani MA, Ryan K, Nehls MC, Wilson V, Evans MJ (2000) Eomesodermin is required for mouse trophoblast development and mesoderm formation. Nature 404:95-99.

Schuurmans C, Guillemot F (2002) Molecular mechanisms underlying cell fate specification in the developing telencephalon. Curr Opin Neurobiol $12: 26-34$.

Schuurmans C, Armant O, Nieto M, Stenman JM, Britz O, Klenin N, Brown
C, Langevin L-M, Seibt J, Tang H, Cunningham JM, Dyck R, Walsh C, Campbell K, Polleux F, Guillemot F (2004) Sequential phases of cortical specification involve Neurogenin-dependent and -independent pathways. EMBO J 23:2892-2902.

Sekerková G, Ilijic E, Mugnaini E (2004) Time of origin of unipolar brush cells in the rat cerebellum as observed by prenatal bromodeoxyuridine labeling. Neuroscience 127:845-858.

Sugitani Y, Nakai S, Minowa O, Nishi M, Jishage K, Kawano H, Mori K, Ogawa M, Noda T (2002) Brn-1 and Brn-2 share crucial roles in the production and positioning of mouse neocortical neurons. Genes Dev $16: 1760-1765$

Voogd J (1995) Cerebellum. In: The rat nervous system, Ed 2 (Paxinos G, ed), pp 309-350. San Diego: Academic.

Wang VY, Zoghbi HY (2001) Genetic regulation of cerebellar development. Nat Rev Neurosci 2:484-491.

Wang VY, Rose MF, Zoghbi HY (2005) Math1 expression redefines the rhombic lip derivatives and reveals novel lineages within the brainstem and cerebellum. Neuron 48:31-43.

Weyer A, Schilling K (2003) Developmental and cell type-specific expression of the neuronal marker NeuN in the murine cerebellum. J Neurosci Res 73:400-409.

Wingate RJT (2001) The rhombic lip and early cerebellar development. Curr Opin Neurobiol 11:82-88.

Wurst W, Bally-Cuif L (2001) Neural plate patterning: upstream and downstream of the isthmic organizer. Nat Rev Neurosci 2:99-108.

Zhang L, Goldman JE (1996) Generation of cerebellar interneurons from dividing progenitors in white matter. Neuron 16:47-54. 